\title{
Customer Readiness in Emerging Market towards Vegetable Factories
}

\author{
Tomy Perdana ${ }^{\#}$, Yuanita Handayati ${ }^{*}$, Fernianda Rahayu Hermiatin ${ }^{+}$, Nurpilihan Bafdal ${ }^{\$}$ \\ ${ }^{\#}$ Department of Socio-Economics, Faculty of Agriculture, Universitas Padjadjaran, Sumedang, West Java 4536, Indonesia \\ E-mail: tomy.perdana@unpad.ac.id
}

*School of Business Management, Institut Teknologi Bandung, Bandung, West Java 40132, Indonesia E-mail: yuanita@sbm-itb.ac.id

\author{
${ }^{+}$Agricultural Logistics and Supply Chain System (AGRILOGICS) Research Group, Faculty of Agriculture, Universitas Padjadjaran, \\ Sumedang, West Java 4536, Indonesia \\ E-mail: ferniandarahayu@gmail.com \\ ${ }^{\$}$ Agroindustrial Technology, Faculty of Agroindustrial Technology, Universitas Padjadjaran, Sumedang, West Java 4536, Indonesia \\ E-mail: nurpilihanbafdal@yahoo.com
}

\begin{abstract}
Consumers are nowadays aware of the importance of product availability, as well as the quality and safety of the vegetable content they consume. Vegetable production in emerging markets, especially in contemporary Indonesia, still demonstrates erratic characteristics in terms of quantity and quality. Since the output static depends on several factors that cannot be controlled, such as weather, pests, and any other environment condition. Vegetable factories can represent an alternative solution for managing these problems. However, it is crucial to identify those factors considered relevant by consumers when purchasing vegetables to increase the success of vegetable factories. The survey conducted involved 680 respondents in various major cities throughout Indonesia. The results of the analysis show there to be five product-related factors considered necessary by consumers, namely: availability, physical characteristics, physical condition, branding and packaging and, finally, value for money. This research has practical implication, especially for individual or company that wants to introduce a concept of a vegetable factory in Indonesia. The five-product related factors from this research can be used to define the value proposed to the customer and the marketing strategy to make sure the business will sustain.
\end{abstract}

Keywords— agriculture; fresh product; vegetable factory; factor analysis; emerging market.

\section{INTRODUCTION}

The food supply chain network has several characteristics that distinguish it from other types of supply chains. The first is the uncertainty surrounding product quality and quantity [1]. This is due to the entire production process depending on several factors such as biological variations and seasonality, together with other random considerations, including the weather, pests, and biological hazards. Seasonality and weather conditions influence cultivated food products, especially those who are plant-based. For such products, their availability and quality throughout the year will depend very much on the current season and prevailing weather.

The uncertainty surrounding vegetable availability and quality can be minimized through the application of vegetable factory technology optimizes the cultivation environment to the point where it is unaffected by external seasonal conditions [2]. Through the application of such technology, the effect of seasonality and other environmental factors on the quantity and quality of plantbased products can be minimized. Moreover, plant factories have the potential to enable the cultivation of plant-based products in locations where critical environmental factors such as land and weather conditions are unsuitable for the cultivation of such products [3].

One type of plant factory which is specialized in producing vegetable products is called the vegetable factory. Several advantages could be gained from the utilization of vegetable factories in producing vegetable products [3]. The first one is that the production of the products could be conducted throughout the year without being limited by weather and seasons. As previously mentioned, this could minimize the uncertainty of vegetable products both in quantity and quality. Also, this can ensure that the vegetable would be available throughout the year, even though the 
outside weather supposedly could not support cultivation. An additional advantage would be that the quality of products could be controlled thoroughly to result in the qualities demanded by the market, especially in terms of the size and shape of the products. It is also stated that the vegetables produced in the vegetable factory would be free from the usage of pesticides, as they do not come into contact with pests, and have maximized nutritional content compared to the vegetables cultivated in standard ways. Lastly, the vegetable factory requires a smaller number of workers, so there would be a possibility to decrease the production cost. However, it should be remembered that the plant factory would require more significant investment at the beginning, especially related to the construction of the factory and the installment of the facilities.

The advantages of the vegetable factory having been defined. It could be argued that there is considerable potential for applying this type of business model in an emerging market such as Indonesia. This is particularly the case since the agricultural sector remains one of the largest industries within the country. The national demand for fruit and vegetables shows that a significant market opportunity exists to develop a healthy lifestyle-oriented fruit and vegetable industry.

It is characterized by an increase in economic growth above $5 \%$ per year, which has led to an increase in income per capita of the Indonesian population to above US\$ 3,500. In line with the increasing income of the population, consumer demand for vegetable products has changed, not only to meet food needs according to product standards and food safety but has evolved towards a healthy lifestyle. However, its leading players still consist of small actors or farmers who fail to realize the importance of market supply stability. This situation indicates the existence of a business opportunity for modern agricultural businesses such as the "plant factory" system. However, before its direct implementation, a study of Indonesian customer willingness to purchase vegetable factory-processed products is deemed necessary.

This research contributes to the literature and practice on consumer buying behavior towards the vegetable factory. It explores how, in addition to the descriptive statistics of the target population, factors promoting the purchase of vegetable factory-processed products could be employed for marketing purposes. The article is organized as follows. The first section discusses the potential market of the vegetable factory, especially in Indonesia. The following section describes the value proposed by the vegetable factory. The third and fourth sections describe the methodology and research results on consumer behavior toward the vegetable factory. The last section discusses the conclusion and contribution of the research.

\section{MATERIALS AND METHOD}

Previous studies on consumer behavior mention that customer decision on purchasing a product or service is defined by consumer's demographic and socio-economic characteristics and consumer motivations of purchasing intention of vegetables [4]. In this study, the demographic and socio-economic variables are gender, educational background, employment status, income, and family size.
The consumer motivations of purchasing intention of vegetable variables are listed below. The attributes perceived to be relevant to consumers, the beliefs and intentions they hold, and the behavior they develop are crucial to understanding their behavior (Table 1).

TABLE I

Attributes of Consumer BeHAVIOR RELATING to Vegetable Plant FACTORIES

\begin{tabular}{|l|l|l|}
\hline $\begin{array}{c}\text { Factor } \\
\text { ID }\end{array}$ & \multicolumn{1}{|c|}{ Factor } & \multicolumn{1}{|c|}{ Source } \\
\hline FC01 & Price (100 gram) & {$[5],[6],[7],[8]$} \\
\hline FC02 & Shape & {$[6]$} \\
\hline FC03 & Size & {$[6]$} \\
\hline FC04 & Color & {$[6]$} \\
\hline FC05 & Freshness & {$[6],[7]$} \\
\hline FC06 & Aroma & {$[6]$} \\
\hline FC07 & Taste & {$[5],[6],[7],[9],[10]$} \\
\hline FC08 & Nutrition & {$[5],[6],[9],[10]$} \\
\hline FC09 & Smoothness & {$[6]$} \\
\hline FC10 & Cleanliness & {$[6]$} \\
\hline FC11 & Storage durability & {$[6]$} \\
\hline FC12 & Pesticide-free & {$[9]$} \\
\hline FC13 & Organic & {$[7],[10]$} \\
\hline FC14 & Brand & {$[6]$} \\
\hline FC15 & Label & {$[6]$} \\
\hline FC16 & Packaging & {$[6]$} \\
\hline FC17 & Packaging Size & {$[6]$} \\
\hline FC18 & Producer Location & {$[10]$} \\
\hline FC19 & Local Producer & {$[7]$} \\
\hline FC20 & Ease of product purchasing & {$[5],[7]$} \\
\hline FC21 & Market Service & Consideration for \\
& & Indonesian society \\
\hline FC22 & Availability of product & {$[6]$} \\
\hline FC23 & Information on product & {$[6]$} \\
& usage & \\
\hline
\end{tabular}

The data for this study were collected through a survey questionnaire consisting of several sections. Gender, age, education, and family size are personal information that contained and became the first section of the questionnaire. The second section contained questions relating to consumer vegetable purchasing behavior. The third section featured questions related to their motivation in purchasing vegetables with operational variables being the indicators defined in Table 1. Respondents were asked to rate the variables relating to their motivation in purchasing vegetables using the Likert scale, with value one being 'Not motivating' and value five being 'Very motivating.'

The target sample of the survey was selected using a purposive sampling technique which is used to obtain samples that can represent the target population based on the subjective judgment of an expert [11]. The samples were selected in a non-random manner based on the unique characteristics of the target population. The 680 survey respondents constituted end-users who regularly consume vegetables and reside in major conurbations that dominated by the middle to upper-income levels including Jakarta, Semarang, Surabaya, Tangerang, Depok, Denpasar, Bogor, 
Bekasi, Bandung, and Balikpapan. These cities were selected basis on their having become a magnet for various lifestyle-oriented businesses. More than $50 \%$ of the total modern market in Indonesia is concentrated in and expanding from these locations.

In this research, an exploratory factor analysis methodology was utilized, which is especially pertinent when the underlying structure of a set of known variables is sought [12]. Variables can also be grouped into several constructs called factors, each of which will have its loadings for individual observable variables. The methodology adopted is also useful in determining the most potent contributory motivational factor influencing this population in its vegetable purchasing decisions. Through analysis of the loadings and the proportional variance of the factors, variables must only load on certain factors, while the fit of a particular model is examined.

\section{RESULTS AND DISCUSSION}

\section{A. General Characteristics of Vegetable Consumers}

The descriptive statistics of the respondents are presented in Table 2. Most survey respondents were female, with only $37 \%$ male. This result shows that nowadays, a woman represents the majority in population and has a role not only as a buyer but also influencer [13]. 85\% of the respondents had undertaken at least undergraduate level higher education and were drawn from families containing a maximum of four members. The survey results show that $78 \%$ of respondents were employed, $17 \%$ were housewives, and $5 \%$ consisted of the retired, students, and unemployed. The nature of the employment of respondents was divided between the following categories: private employees $(45 \%)$, entrepreneurs (17\%), civil servants (16\%) and others (3\%). More than half of the respondents had a monthly income of between IDR 5 million and IDR 10 million, while $20 \%$ of respondents had one in the range of IDR 10 million to IDR 15 million. $18.5 \%$ of respondents earned between IDR 3 million and IDR 5 million, while the remaining $12 \%$ of respondents reported an income of more than IDR 15 million.

TABLE II

DESCRIPTIVE StatisTics OF THE SAMPLE POPULATION

\begin{tabular}{|l|l|c|c|}
\hline \multirow{2}{*}{ Gender } & Male & Quantity & Percentage \\
\cline { 2 - 4 } & Female & 188 & $37 \%$ \\
\hline Education & No formal education & 492 & $73 \%$ \\
\hline \multirow{5}{*}{ Family Size } & High School & 1 & $0.14 \%$ \\
\cline { 2 - 4 } & Bachelor Degree & 48 & $14 \%$ \\
\cline { 2 - 4 } & Above Bachelor Degree & 117 & $68 \%$ \\
\cline { 2 - 4 } & 4 people or fewer & 476 & $70 \%$ \\
\cline { 2 - 4 } & More than 4 people & 204 & $30 \%$ \\
\hline
\end{tabular}

The frequency of vegetable purchases that is most often done by respondents is daily purchases (34\%), 2-3 times in one week $(31 \%)$ and once a week $(20 \%)$. The frequency of purchasing vegetables can be influenced by the type of work of the respondent. Many homemakers, civil servants, and respondents who have not worked do purchase vegetables every day, whereas private employees and entrepreneurs do vegetables purchases at least 2-3 times a week or once a week and buy in large quantities so that they can be stored for the next few days.

In $55 \%$ of cases, the decision to buy vegetables was reached predominantly by the prospective purchasers, almost invariably women. This result is agreed that women buy vegetable in larger service and more frequently than men [13]. As many as $18 \%$ of respondents stated that wives played a role in vegetable purchasing decisions, while 47 respondents, representing approximately $7 \%$ of the total respondents, indicated that such decisions took the views of all family members into account. Meanwhile, vegetable purchasing decisions based on parental requirements and preferences constituted only $6.3 \%$ (43 respondents), and those taken by children accounted for $5.8 \%$ (40 respondents). Only a small percentage of vegetable purchasing decisions (4\%) were determined by the husband, the same figure for those influenced by household assistants. For the rest, representing less than $1 \%$ of respondents (5), vegetable traders, friends or neighbors influenced the decision to buy vegetables.

Furthermore, related to the customer buying decision, 52\% of respondents plan to purchase vegetables before buying (plan buying). Planning for purchasing vegetables is based on the food menu decision that will be presented as well as part of the family budget arrangement, which is usually managed by the wife/mother/woman while as many as $47 \%$ of respondents answered that purchasing vegetables is done by impulse buying or unplanned purchases. The impulse buying happened because when shopping, consumers see that the vegetables provided in the market have an attractive appearance, attracted by promotions, or the prices of vegetables offered are lower than the market where vegetables are usually purchased. However, about $1 \%$ of respondents answered that sometimes buying vegetables is done with plan buying, if the respondent has arrived at the market place of shopping, sometimes respondents do impulse buying due to promotion or lower prices of vegetables and attractive vegetable displays.

The types of vegetables preferred by consumers are those in the form of fresh products, packed vegetables, bulk vegetables, and fresh-cut vegetables, while ready-to-eat and ready-to-cook vegetables do not represent the first choice of consumers for everyday fare. Moreover, consumers regard fresh vegetables as preferable if the price offered is favorable. The explanations above are categories as customer behavior. The action was given by individuals that directly involved in obtaining and using economic value [14], [15].

\section{B. Factors Influencing Vegetable Consumption}

Factor analysis shows that interrelationships between variables or attributes influence consumer purchasing behavior. For this study, data relating to customer motivation in purchasing vegetables were processed using an $\mathrm{R}$ studio program for factor analysis.

The 680 observations of 23 indicators of vegetable purchase decisions were initially subjected to analysis by a Kaiser-Meyer-Olkin Statistics (KMOS) test to determine the goodness-of-fit. The KMO-Criterion score of 0.88 for the data exceeded the recommended value of 0.6 was considered sufficiently high for the data to be further analyzed using the 
factor analysis method [16]. The Measures of Sampling Adequacy (MSA) for all indicators exceeded 0.5, further confirming the fitness of the data. A screen plot was subsequently elaborated to establish the possible number of factors to be developed from the indicators in which the difference in variances between five factors and six factors was already seen to be insignificant. Thus, for this model, it could be determined that the possible number of factors was five.

About the initial results, when the cut-off of 0.5 loadings for each indicator was applied to the factors, the indicator of FC01 (the price for every 100 grams) had no loading in many cases. This implies that price is not a significant variable to be included in defining customer behavior when purchasing vegetables. The price is not associated with the decision to purchase fresh produce [17], [18]. Therefore, FC01 indicators should be excluded from the model.

TABLE III

GROUPS OF VARIABLES DEFINED BY FACTOR ANALYSIS

\begin{tabular}{|c|c|c|c|}
\hline Factors & $\begin{array}{l}\text { Proportion } \\
\text { Variance }\end{array}$ & Variables & $\begin{array}{l}\text { Variable } \\
\text { Loading }\end{array}$ \\
\hline \multirow{8}{*}{$\begin{array}{l}\mathrm{RC} 1 \\
\text { Main Value } \\
\text { Proposed }\end{array}$} & \multirow[t]{8}{*}{0.226} & FC06 - Aroma & 0.747 \\
\hline & & FC07 - Taste & 0.730 \\
\hline & & FC08 - Nutrition & 0.801 \\
\hline & & $\begin{array}{l}\text { FC11 - Storage } \\
\text { Durability }\end{array}$ & 0.587 \\
\hline & & FC12 - Pesticide-free & 0.767 \\
\hline & & FC13 - Organic & 0.797 \\
\hline & & $\begin{array}{l}\text { FC19 - Local } \\
\text { Producer }\end{array}$ & 0.636 \\
\hline & & $\begin{array}{l}\text { FC23 - Usage } \\
\text { Information }\end{array}$ & 0.631 \\
\hline \multirow{3}{*}{$\begin{array}{l}\mathrm{RC} 2 \\
\text { Surface } \\
\text { Texture }\end{array}$} & \multirow[t]{3}{*}{0.100} & FC05 - Freshness & 0.735 \\
\hline & & FC09 - Smoothness & 0.669 \\
\hline & & FC10 - Cleanliness & 0.833 \\
\hline \multirow{3}{*}{$\begin{array}{l}\text { RC3 } \\
\text { Access to } \\
\text { Product }\end{array}$} & \multirow[t]{3}{*}{0.108} & $\begin{array}{l}\text { FC20 - Purchasing } \\
\text { Ease }\end{array}$ & 0.814 \\
\hline & & $\begin{array}{l}\text { FC21 - Market } \\
\text { Service }\end{array}$ & 0.792 \\
\hline & & $\begin{array}{l}\text { FC22 - Product } \\
\text { Availability }\end{array}$ & 0.829 \\
\hline \multirow{3}{*}{$\begin{array}{l}\mathrm{RC} 4 \\
\text { Visual } \\
\text { Appearance }\end{array}$} & \multirow[t]{3}{*}{0.096} & FC02 - Shape & 0.824 \\
\hline & & FC03 - Size & 0.833 \\
\hline & & FC04 - Color & 0.576 \\
\hline \multirow{4}{*}{$\begin{array}{l}\text { RC5 } \\
\text { Brand and } \\
\text { Packaging }\end{array}$} & \multirow[t]{4}{*}{0.165} & FC14 - Brand & 0.819 \\
\hline & & FC15 - Label & 0.827 \\
\hline & & FC16 - Packaging & 0.808 \\
\hline & & $\begin{array}{l}\text { FC17 - Packaging } \\
\text { Size }\end{array}$ & 0.797 \\
\hline
\end{tabular}

The FC18 indicator (Producer Location) had loadings, also referred to as cross-loadings, in more than one factor. This result occurred because there was another variable, namely FC19 (Local Producer) that similarly highlights the importance of the geographic position of farmers. FC18 is overlapping or does not significantly affect consumer decisions to purchase vegetables when compared to FC19.
The results illustrate that local farmers have produced purchased vegetables without needing to know their exact location. Therefore, FC18 indicator was not included in the model. The factor analysis result for the data, eliminating the indicators of FC01 and FC18, will result in no crossloadings between the indicators and the factors.

The elimination of the FC18 indicator resulted in a KMOCriterion score for the data of 0.87 . However, it was still considered to be sufficiently high for the factor analysis process. The resulting screen plot differed little from the initial one which confirmed that the number of factors for this data remained at five. As presented in Table 3, the RC01 and RC05 factors had the highest loadings compared to other factors. Therefore, it can be argued that these factors exerted the most significant influence on customer decisions to purchase vegetables.

Based on the factor analysis methodology, there are five groups to which the variables could be assigned. The first group, which accounts for $22.6 \%$ of the total variance, can be categorized as the central values that need to be prioritized by vegetable factories. In this group, the following variables were present: aroma, flavor, and nutritional value, and shelf life, absence of pesticides, organic characteristics, local production, and instructions for use. The presence of a wide variety of variables within this group is evident. However, they demonstrate sufficient similar patterns to be considered a single factor group. The aroma, taste, and shelf life of vegetable products can be deemed to constitute their value. Nutritional value, absence of pesticides, and organic characteristics could be regarded as product-related health issues.

Furthermore, local producer information and directions for use can also be said to form part of the product value. Those variables are under the previous study, which mentions that buying behavior also defined by specific product attributes namely nutritional, taste, and freshness [19]. Moreover, the local producer information can be other consumer's purchase motives [15], [20].

Issues regarding health and food security are the main things for consumers to buy vegetable products that will be consumed by all family members. Especially for respondents who have babies/toddlers and the elderly, they will be more focused on providing products that are safe for consumption. This is in line with the research of [21].

The second factor identified through the analysis, which accounts for 16.5 percent of the total variance, can be categorized as the branding and packaging of vegetable products. This means that the variety of the variables in this factor could explain they are the second-highest population in the model. In this factor, there are four variables present: branding, labeling, packaging, and size of packaging.

The third factor is related to customer product access, accounting for 10.8 percent of the total variance. This factor group includes the variables of ease of purchase, market service, and product availability [22]. Thus, this factor is related to whether the product is readily available to the customer who can purchase it with ease. The market service provided to the customer, both when purchasing the product and during the after-sales period is also considered in this factor. 
The fourth factor, which accounts for 10 percent of the total variance, is categorized as the surface texture of vegetable products. The variables of freshness, smoothness, and cleanliness are included in this factor. These variables refer to the surface texture of the product experienced by consumers, as in whether the product is fresh, smooth, and sufficiently clean for the customer. The freshness, smoothness, and cleanliness can also represent the primary component of eating pleasure [14].

The final factor has the lowest proportion variance of 9.6 percent of the total variance. It comprises variable shape, size, and color; in other words, the visual appearance of the vegetable product. These variables also mentioned that the essential factors defined by the consumption of fresh products [23]. This factor differs from the second factor in terms of the physical state of the product, as there could be variation in the appealing shape, size, and color of a vegetable product.

\section{CONCLUSION}

In Indonesia, the consumption of vegetables continues to increase every year. This situation shows that a commercial opportunity exists to develop a healthy lifestyle-oriented vegetable business. The contemporary vegetable industry in Indonesia remains dominated by small-scale farmers with limited knowledge of and no access to the latest agriculture product cultivation technology. A great opportunity exists to apply modern knowledge and technology in producing vegetables, one of which is to implement a factory system. However, the investment necessary to establish such a system is considerable. Therefore, it is imperative to determine those factors which vegetable producers or suppliers need to consider when establish a vegetable factory system.

The survey involved 680 respondents from various regions within Indonesia. The data processing results show the vegetable purchasing decisions of consumers to be influenced by five major factors including price, branding and packaging, product access, surface texture, and visual appearance of the vegetables.

The factor analysis results indicate the overriding importance for consumers in Indonesia when implementing the relatively novel vegetable factory concept of aroma, taste, nutrition, shelf life, non-use of pesticides, organic production methods, local producers, and guidance on use. These factors are consistent with those present in vegetable factories where all components of plant growth such as temperature, humidity, carbon dioxide levels, and plant nutrients are supported by technology, with the result that vegetable production can attain maximum levels of both quality and quantity. The vegetable factory is designed to have minimal influence on the external environment. The damage to plants caused by viruses, bacteria, fungi, and insects can be minimized, as can the use of pesticides. Therefore, the vegetables will be free of biological and chemical contamination. Another critical factor meriting consideration is that of nutritional data. Contemporary consumers do not only care about the availability of items they buy but also want to be well informed about what they consume.
The second factor, perceived as an essential factor by consumers is that of branding and packaging. Brand awareness must be first developed, supported by information on labels and packaging that projects a positive impression on consumers. Besides, the concept of local producers also needs to be communicated to customers of vegetable factories. It offers an urban farming concept, applicable in built-up areas with limited land, which provides a safe, fresh product. The appearance turned out not to be a significant factor for consumers in deciding which vegetables to buy compared with the other factors mentioned above.

Another factor differentiating vegetable factories from conventional planting is product customization, which can be achieved by the vegetable factory. This is because the system involves a production process and post-harvest handling supported by technologies capable of customizing taste, nutrition, cleanliness, and freshness.

The practical implication from the research result is that it can be used as a guideline to develop vegetable factories in a developing country, especially in Indonesia. The factors that are perceived necessary by customers show Indonesia customer's characteristics in buying the vegetable product. It is also critical insight for vegetable factory business in defining the marketing strategy for their product.

This research has limitations related to the case study that only limited to the Indonesia context. Generalization of an important factor in the vegetable factory for other emerging markets is needed by defining the customer characteristics in other developing countries or by conducting several interviews or surveys. Further study on the Indonesia context needs to be conducted; it is also essential to have a cluster analysis combined with factor analysis to have a detailed picture of market segmentation for Indonesia vegetable customers and find the relevance segment for the vegetable factory.

\section{ACKNOWLEDGMENT}

The authors gratefully acknowledge Ministry of Research, Technology, and Higher Education, Republic of Indonesia and Universitas Padjadjaran for research funding of the National Priority Research Program.

\section{REFERENCES}

[1] J.G.A.J. Van der Vorst, A.J.M. Beulens, and P. Van Beek, "Modelling and simulating multi-echelon food systems". European Journal of Operations Research., vol. 122 no. 2, pp. 354-366. Apr. 2000 .

[2] B. Oguntoyinbo, M. Saka, Y. Unemura, and J. Hirama, "Plant factory system construction: cultivation environment profile optimization". Environmental control in biology., vol. 53 no.2, pp.77-83. 2015.

[3] W. Yamori, G. Zhang, M. Takagaki, and T. Maruo, "Feasibility study of rice growth in plant factories". Journal of Rice Research., vol. 2 no. 1, pp. 119-125. Feb. 2014.

[4] O. Varela, W.C. Huang, and S.E. Sanyang, "Consumer behavior and preference in the fruit markets of Taiwan". Agricultural Economics and Marketing Journal., vol. 2 no.1, pp 19-28. 2009.

[5] R. Nandi, W. Bokelmann, N.V. Gowdru, and G. Dias, "Factors Influencing Consumers' Willingness to Pay for Organic Fruits and Vegetables: Empirical Evidence from a Consumer Survey in India”. Journal of Food Products Marketing, vol. 23 no.4, pp. 430-451. May. 2017.

[6] P. Ragaert, W. Verbeke, F. Devlieghere, and J. Debevere, "Consumer perception and choice of minimally processed vegetables and 
packaged fruits". Food Quality and Preference., vol. 15 no.3, pp. 259-270. Apr. 2004.

[7] E. Brown, S. Dury, and M. Holdsworth, "Motivations of consumers that use local, organic fruit and vegetable box schemes in Central England and Southern France". Appetite,vol. 53 no.2, pp 183-188. Oct. 2009.

[8] J.Aschemann-Witzel, and S. Zielke. "Can't buy me green? A review of consumer perceptions of and behaviour toward the price of organic food". Journal of Consumer Affairs, vol. 51 no.1, pp 211-251. Mar. 2015.

[9] S. Padel, and C. Foster. "Exploring the gap between attitudes and behaviour: Understanding why consumers buy or do not buy organic food”. British Food Journal., vol. 107 no.8, pp. 606-625. Aug. 2005.

[10] S. Chakrabarti. "Factors influencing organic food purchase in Indiaexpert survey insights". British Food Journal, vol. 112 no.8, pp. $902-$ 915. Aug. 2010.

[11] P.J. Lavrakas. Encyclopedia of survey research methods. Sage Publications Inc, Thousand Oaks California, USA. 2008.

[12] M. Norris, and L. Lecavalier. "Evaluating the use of exploratory factor analysis in developmental disability psychological research". Journal of Autism and Developmental Disorders, vol.40 no.1, pp. 820. Jan. 2010.

[13] G.D. Thompson, and J. Kidwell. "Explaining the choice of organic produce: cosmetic defects, prices, and consumer preferences". American Journal of Agricultural Economics, vol. 80 no.2, pp. 27787.1998.

[14] H.N. Utami, A.H. Sadeli, and T. Perdana. "Customer Value Creation of Fresh Tomatoes Through Branding and Packaging as Customer Perceived Quality". in International Society for Southeast Asian Agricultural Sciences-Philippines, 2016, paper 22, pp.123-136.
[15] A.H. Sadeli, H.N. Utami, and R. Rahmanissa. "Does Customer Satisfaction on Product Quality Illustrates Loyalty of Agricultural Product”. International Journal of Applied Business and Economics Research, 2016, paper 4.1, pp.223-232.

[16] B.D. Hill. "Sequential Kaiser-meyer-olkin Procedure as an Alternative for Determining the Number of Factors in Commonfactor Analysis: a Monte Carlo Simulation," Doctoral dissertation, Oklahoma State University. 2011.

[17] E. Winkler. G. Turrell, and C. Patterson. "Does living in a disadvantaged area entail limited opportunities to purchase fresh fruit and vegetables in terms of price, availability, and variety? Findings from the Brisbane Food Study," Health and Place, vol. 12 no. 3, pp. 741-748. Dec. 2006.

[18] T. Pearson, J. Russell, M.J. Campbell, and M.E. Barker. "Do 'food deserts' influence fruit and vegetable consumption? A cross-sectional study," Appetite, vol. 45 no. 2, pp. 195-197. Oct. 2005.

[19] A. Davies, A.J. Titterington, and C. Cochrane. "Who buys organic food? A profile of the purchasers of organic food in Northern Ireland," British Food Journal, vol. 97 no.10, pp. 17-23. Nov. 1995.

[20] O. Orji. "Major Classic Consumer Buying Behavior Models: Implications for Marketing Decision-Makin," Journal of Economics and Sustainable Development, vol. 4 no.4, pp. 164-72. 2013.

[21] V. Falguera, N. Aliguer, and M. Falguera. "An integrated approach to current trends in food consumption: Moving toward functional and organic products?" Food Control, vol.26 no.2, pp.274-281.Aug. 2012.

[22] R. Silverstone. "Organic farming: food for the future?" Nutrition and Food Science, vol. 93 no.5, pp. 10-14. 1993.

[23] S.C. Tan. "Determinants of eating quality in fruit and vegetables," in Proceedings of the Nutrition Society of Australia, 2000, 24,pp 183190. 